\title{
\begin{tabular}{l|l} 
Mibraries & DSpace@MIT
\end{tabular}
}

\author{
MIT Open Access Articles
}

\section{Historical Experiments in Students' Hands: Unfragmenting Science through Action and History}

The MIT Faculty has made this article openly available. Please share how this access benefits you. Your story matters.

Citation: Cavicchi, Elizabeth Mary. “Historical Experiments in Students' Hands: Unfragmenting Science through Action and History." Science \& Education 17, no. 7 (August 2008): 717-749.

As Published: http://dx.doi.org/10.1007/s11191-006-9005-2

Publisher: Springer-Verlag

Persistent URL: http://hdl.handle.net/1721.1/87089

Version: Author's final manuscript: final author's manuscript post peer review, without publisher's formatting or copy editing

Terms of Use: Article is made available in accordance with the publisher's policy and may be subject to US copyright law. Please refer to the publisher's site for terms of use. 


\title{
Historical Experiments in Students' Hands: Unfragmenting Science through Action and History
}

\author{
ELIZABETH CAVICCHI \\ Dibner Institute for the History of Science and Technology, MIT, Cambridge MA, USA \\ email: Elizabeth_Cavicchi@post.harvard.edu ecavicch@mit.edu
}

\begin{abstract}
Two students, meeting together with a teacher, redid historical experiments. Unlike conventional instruction where science topics and practices often fragment, they experienced interrelatedness among phenomena, participants' actions, and history. This study narrates actions that fostered an interrelated view. One action involved opening up historical telephones to examine interior circuitry. Another made sound visible in a transparent air column filled with Styrofoam bits and through Lissajous figures produced by reflecting light off orthogonal nineteenth century tuning forks crafted by Koenig and Kohl. Another involved orienting magnetic compasses to reveal the magnetism of conducting wires, historically investigated by Oersted and Schweigger. Replicating Homberg's triboluminescent compound elicited students' reflective awareness of history. These actions bore pedagogical value in recovering some of the interrelatedness inherent in the history and reintroducing the wonder of science phenomena to students today.
\end{abstract}

\section{Introduction}

We typically turn on lights or answer the phone without thinking about what makes these things work. Out of view, as if off-stage, everything runs by an interplay of electricity, magnetism, sound, and light. That complex integration is concealed by design and by the advanced miniaturized technologies in use today. Nor is it addressed in most instructional materials, which treat sound and electricity as separate topics.

In historical times, it was different. Magnetic needles turned, sparks flew, and sounds crackled when electrical circuits were switched, rendering these phenomena integrated instead of isolated. Historical apparatus were often built with exposed workings. For example, it was easy to see the paths directing electricity in wires, and light through optical elements. This open access facilitated the original investigators in improvising experiments and in apprehending the interrelatedness of physical phenomena. These same facilitating properties endow the experimental materials of the past with continuing potential for engaging science learners today.

While most science curriculum marginalize the historical experience into footnotes and glosses, some alternatives center around recreating historical experiments, debates and apparatus. During the late 1960s, Devons and Hartman (Devons \& Hartman 1970, Hoddeson 1971) pioneered a student laboratory containing thirty set-ups of historical experiments. Unlike "canned" standard lab exercises, they realized that experiments redone with historical materials raise genuine problems that challenge students' observation skills and thinking. Science history is not alone in its exclusion from school science; nature observation and investigation are also rarely conducted. To prepare teachers for introducing such experiences in their classrooms, Kipnis (1996) offered teacher workshops. By doing qualitative activities with historical origins and everyday objects, the participating teachers became practiced in looking at phenomena and reflecting on how science discoveries are made.

These related themes of observation and investigation have also emerged in prior and more recent instructional projects to combine history, experiment and science (Conant 1957, 
Crawford 1993, Holton 2002, Teichmann 1999). In one course, undergraduates' struggles with constructing their own timer for the Galilean inclined plane showed the depth of their engagement: "history can be an important source of questions to pose, not just a series of actual discoveries to learn" (Allchin, 1999, 622). With this kind of involvement in mind, another course purposefully chose the case of Alexander Graham Bell's telephone to stimulate students to invent actual devices and take stock of inventive processes in history and their own work (Gorman 1998). Invention arose more in discussion, than lab, when Peter Heering (2000) taught high school students with historical readings and taking shocks from Leyden jars they made in the lab. Students became increasingly animated while discussing observations, realizing inadequacies in their explanations, and - when the class' authority figure failed - drawing upon personal creativity to make sense of electrostatics. These student discussions are one example of the University of Oldenburg's extensive program of training physics teachers through replicating historical instruments (Heering 2003).

To these examples of educational values to be gained when science students redo historical experiments, the study presented here adds the finding that students may realize the interrelatedness of different-seeming phenomena. Science students often have the contrary perception. In analyzing in-depth interviews of physics students, David Hammer (1994) found that whereas for some students, physics knowledge coheres as an interdependent system, for others it is a set of isolated pieces lacking unifying threads. Standard curricula contribute to the "pieces" view by treating as separate topics such phenomena as sound, electricity and light and by emphasizing techniques and formula rather than a wider picture (Van Heuvelen 1991). Some efforts to redress this fragmentation pre-organize the course curriculum to make explicit the big ideas and the links, such as those between electricity and magnetism (Bagno 1999). Alternative to these curricular strategies where connective themes are built-in, Hammer (1995) demonstrated that students can spontaneously propose examples and seek out interrelations among their examples. As Hammer's students discussed the possible paths taken by a ball thrown upward from a moving cart, they wondered about interplanetary space travel. Through discussing this new topic, doing the cart experiment, and reading an excerpt from Galileo, these students looked for coherence in understanding various motions, although their arguments were not always "correct".

The history of science with its experimental legacy has yet to be plumbed as an educational resource for countering the fragmenting of science knowledge. Arons (1982) identified such an educational potential in the wealth of experience with disparate phenomena and materials that historical experimenters like J. J. Thomson brought together while dealing with puzzling observations. Historical examples provide students with opportunities for considering how experimenters coordinated the workings and limits of their apparatus with what was happening. Arons observed that historical exercises contrast with conventional problem-solving tasks by engaging students to think deeply about phenomena, to appreciate "the unity of physics", and to stretch in what it means to them to learn. Students begin to see the "guesswork" and uncertainty of doing science, which is unlike their textbook-instilled dependence on "pat answers" (Arons 1982, p. 19).

Aron's insight that students' deep involvement with something engenders awareness of how phenomena interrelate and a curiosity that cannot be satisfied by easy answers, is shared by others whose teaching immerses students in direct experiences with science and other subject areas (Duckworth 2001, Hughes-McDonnell 2000, Cavicchi 1999, Hawkins 1990, Morrison 1985). For example, a group of high school students explored nineteenth century butter molds and formed their own interpretations of these artifacts and the historical working environments and social settings. The teacher supported this learning by using Eleanor Duckworth's 
methodology (Duckworth 2005, 2001, 1999, 1991) of Critical Exploration (Extended Clinical Interviewing), derived from the insights of Piaget (1926, 1936) and Inhelder (1974). Critical Exploration involves engaging students' curiosity with something complex, encouraging them to interact with it directly and reflectively, and providing new materials and questions that add further options to do and notice. Through documenting her students' work as it evolved, the teacher found:

that the students did not simply extract statements of fact from historical evidence. They did not separate the artifacts' physical capacities, practical purposes, and cultural functions, but seamlessly demonstrated and recreated them, underscoring their interdependence. (McKinney 2004, p. iv-v) An integrated picture of butter-making and marketing emerged without the fragmenting of isolated facts, and unquestioned acceptance of authoritative views, that often characterize school history lessons.

As with the butter mold investigation, the study presented here adapts Critical Exploration methodology to facilitate investigative learning with materials and history. Two students along with me, as their teacher and researcher, experimented with phenomena of sound, electricity, magnetism, and light. We documented these activities in journals kept by one student (Stevens 2005) and me (Cavicchi 2005), and through photography by the other student, and me.

Learning in these experiences is expressed through doing, interacting, looking, wondering, trying; likewise, teaching is also action. Some actions emerged as provocative pedagogy. In the sense expressed here, pedagogical activity is combined of teaching and learning, such as by making available something to do or notice that takes participants further in what they wanted to understand. One such pedagogically productive action is that of opening something up, where exposed mechanism and circuitry raised questions - and offered hints -about the historical device's workings. Another action involved making visible something about sound, which to one student had seemed only for hearing. A third action concerned orienting materials in ways that matter for producing particular physical effects - in this case, the magnetism of conducting wires. And an action of thoughtful, integrative depth arose as the students became aware of history having ways different from ours.

The body of this paper narrates examples where these actions were expressed within class sessions. A full story of the course experiences is not attempted here $;{ }^{1}$ other experiments, readings and discussions intervened. Rather, the example narratives relate "guesswork" (valued by Arons) going on in actions that occur in the course of experimenting yet have pedagogical import. Interrelatedness among science phenomena, materials, and actions done with them, emerges for the students, and has a functional role in what they do and interpret.

\section{Setting}

Weekly sessions with the students constituted a pilot study for a new lab seminar that was supported by Jim Bales and the Edgerton Center staff, Markos Hankin along with MIT's Physics Demonstration staff, and the Dibner Institute for the History of Science and Technology. The lab seminar is offered for academic credit as an undergraduate elective. Both students used it to satisfy degree requirements for lab-work. A version of this course has since been adapted for a public university, where it fulfills an undergraduate requirement in general science.

Making use of strengths in the local collections (such as repositories of historical telephones, light-bulbs and tuning forks), in advance I prepared a syllabus including lab activities, readings, and field trips around such themes as 'experimenting with things we see around us' and detecting current by sensory and indirect means. We took advantage of unusual access to actual 
historical artifacts, including both observing and hands-on exercises. During sessions, we experimented using improvised and original apparatus and looked for what happened, both as we observed it and as it was described in historical accounts. Changing the syllabus as the course proceeded, I adapted the materials and activities in response to what the students did and talked about each week. For example, to extend their explorations with current's magnetism into several sessions, I brought in a historical coil, a demonstration apparatus powered by a car battery, and additional readings, meanwhile omitting other planned activities.

The students' previous education in science was disparate. Kathleen Stevens, an economics major, spoke about taking high school chemistry and middle school physical science. She always liked to "learn things hands on" (Stevens, May 12, 2005). Richard Whitney, a Media Lab graduate student with a bio-engineering degree, had extensive machine shop, fabrication, and lab experience. At times, this contrast worked productively, for example when Dick varied an experiment to show Kathleen something illustrative, or lent her a helpful book (Challoner 1995). At other times, she did not understand things that were going on. Sometimes she felt "a little awkward and intimidated" (May 12). I felt tentative about moderating the students' joint work, and often observed frustration change into further curiosity and communication.

\section{Opening Something Up}

Together we made field trips to three historical collections: MIT Museum's historical telephones; the Burndy Library's rare science books and electrical instruments, and the Roslindale power substation of Boston's early electric trolley system. During these visits, we not only looked at original apparatus but also had the opportunity to open something up, such as telephones, early printed books, power plant transformer. While the covering might be one material - wood, leather, metal - inside were different materials variously shaped and connected. In opening something up, we, as a group, acted on the artifacts and came to know more about them.

Preceding our visit to the MIT Museum storeroom, assigned readings described learning gained through "personal encounters with objects" (Corn 1996 p. 44) and historical telephones (Fagen 1975, Bell 1875-6). Kathleen, who "knew very little about how telephones work", read about it beforehand, and then saw in a museum transmitter (\#IN 922) cut in half for display, the "flexible disc/diaphragm" that reacts to speech vibrations. Kathleen found it "interesting to compare" museum telephones to those in readings (Stevens, Feb. 24, 2005).

While a direct relation showed between reading and diaphragm, for many other features, the object itself was what we had to go on. This situation became apparent from the start, when we were looking at the outsides of phones. Museum curator Deborah Douglas posed the objects as questions, asking "what do you notice?", "what else?", and "what's in here?" Kathleen and Dick were struck by the single hand-held unit attached by cord to Gray's battery phone (1879, \#IN 888). Dick called it a speaker and a microphone. Holding it in her hands to examine the end disc, Kathleen saw it as taking the place of a separate earpiece and mouthpiece. It had to be held either at the listener's ear or mouth. From this dual-function, Debbie surmised that phone conversations must have had different cuing from what we do now. Talking and listening had to alternate.

The transmitter/receiver's double electric line connected to a pair of posts on a flat oak board. Across the board were two endposts, where Debbie speculated that electricity came into the phone from the outside. Dick and Kathleen commented on a half-spherical bell prominent in the middle of that board. Contrasting it with cell phones and their concealed ringers, Debbie joked "it doesn't play reveille". Beside it was a three-position selector switch. With gloved 
hands, Dick turned it through each setting, wondered what it did, then said he had an idea about it. Maybe the switch had to do whether the person was listening or talking.

Debbie turned the instrument over - the equivalent of opening it up, since it had no outer case. The underside wiring, in grooves cut into the wood board, showed that wire ran from two endposts either to an outer switch position, or to the transmitter/receiver's posts. To Dick, who had made circuits before, this related to his idea about what the switch did. But he did not follow what was happening at the middle position of the switch. Dick became unsure about his idea, "I'm not sure if I'm right. I don't know." Debbie flipped the phone board right-side-up. Dick saw a wood box above the bell, that had gone unnoticed before. Asking "what's in here?", now his question (perhaps coming from awareness that there was something he did not understand) precipitated the action of opening something up.

No one knew what would be inside - even the curator had never disassembled any of these phones! ${ }^{2}$ Debbie unscrewed the box, revealing a small U-shaped bar overwound in black insulated wire. A straighter rod poised across the U's ends, having a longer extension running out of the box, ended in the bell's clapper (Figure 1). Dick recognized the horseshoe as an electrically activated magnet that got the ringer going. He had made a buzzer before, where electricity running in the wiring magnetized the bar so it attracted the rod, which rang the bell and bounced back to ring again. Now the telephone's underside wiring made more sense to him. Perhaps the switch's middle position allowed for ringing.
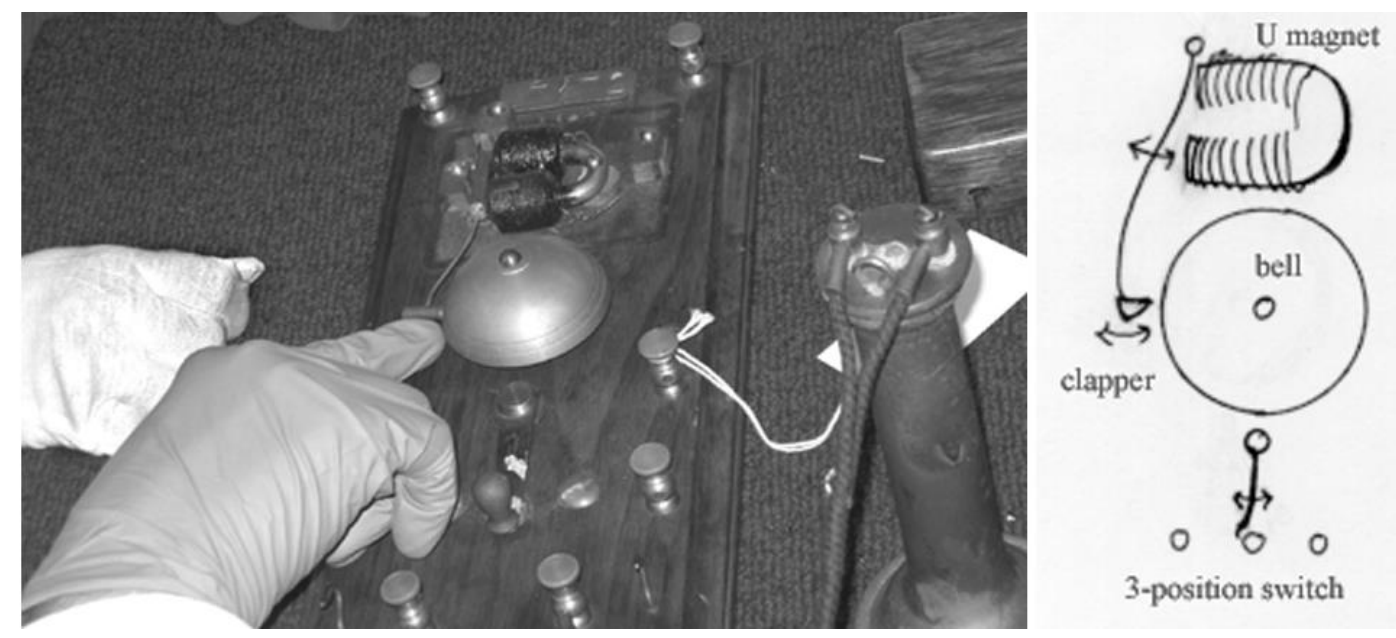

Fig. 1 Left: Dick (gray glove) points out the clapper of the electromagnetic ringer in the Gray battery phone (\#IN 888) to Kathleen (white glove). Right: Diagram showing ringer, clapper, bell and three-position switch.

Turning the phone board over - and over again - showed ever more. Neither side, seen alone, could resolve all Dick's questions - until finally the wood cover came off! Similarly, just following where wires went, and what connected to what, did not disclose the full story. To analyze the ringer's circuit meant seeing that different phenomena of electricity, magnetism, and sound were involved. And Kathleen's attention to the phone's single handheld unit mattered not only for thinking about how it might be used, but also for interpreting the switch.

Debbie pulled out a second phone, a Magneto Wall Set (\#IN 886), and asked the students what they saw. Kathleen immediately said it had two bells with one clapper between them. When Debbie pointed out the nameplate, they noticed it bore the same maker's name (Charles 
Williams Boston) ${ }^{3}$ as that of the previous phone. Debbie asked them to pick out more clues about the two phones. To their comments about the second phone's more finished look and stamped patent date (April 16, 1878), Debbie speculated that it might be a production model.

A deep box encased the second phone's workings. Even after undoing its screws, the lid did not come off for the curator and she asked what to try next. Dick suggested unscrewing the handle of the crank that came through a hole in the lid. Now the lid released. Attached on its underside beneath where the bells were, was a ringer magnet larger than that of the other phone. While Debbie and Kathleen talked about this, Dick concentrated his attention on what was inside the box (Figure 2). A gear took up much of the space, and Dick easily slipped the crank back on the gear's shaft. But the crank wouldn't turn and Dick supposed the gear was frozen.
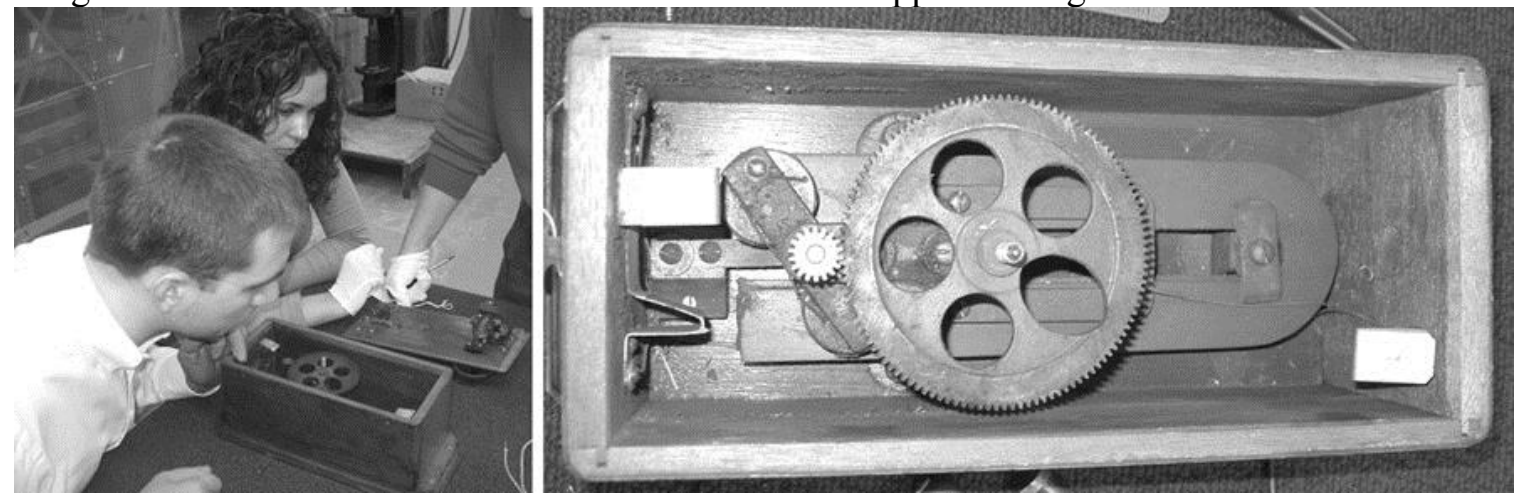

Fig. 2. Left: Kathleen looks at phone lid with its attached ringer, while Dick inspects the box interior. Right: Interior showing gear with oval hole allowing access to screws below. (\#IN 886)

Around the gear's rim were five cutout holes. An asymmetry among these holes provoked Dick's curiosity (Figure 2). Why was one cutout hole oval, while all others were circles? Underneath that gear was more mechanism that Dick conjectured might be a generator, maybe with a flywheel. His hunch was that the oval hole was machined just to the size needed to fit in a screwdriver for repairing the lower mechanism. Borrowing a screwdriver from Debbie's kit, he confirmed this hunch by gently loosening a screw!

Dick's experience as a machinist informed both action and inference about crank and gear. But his queries about this phone's internal mechanism went unresolved during our visit. In itself, that short-falling was pedagogically useful, showing that historical devices operated in ways now outside the scope of mechanical training. A week later, I brought in a book having illustrations of early telephones (Prescott 1878) as a possibility for continuing Dick's interest with them. However, unlike the actual phones, the illustrations did not raise his curiosity. It was not the subject by itself that had gained his interest. Whenever Dick encountered something puzzling, he tried to work it out. It often happened in our sessions, that Dick became involved through something he had not expected to find, either in the historical materials, or the test equipment we used to analyze and reproduce historical effects.

The next phone Debbie brought out had both speaker and microphone (1891, \#IN 857) and matched a photo in an assigned reading (Fagen 1975). It had two boxed enclosures. Debbie opened the lower box first. Inside were loose wires, switches, porcelain. After examining everything carefully, Dick suggested "it looks like the drawer next to the phone always looks. It's random junk." Dick connected everyday habits across the years in interpreting the clutter. However, Debbie offered an alternative; she said several years ago a professor demonstrated this same phone to his classes. Perhaps the bits of wiring are left-over from his demonstration. 
The phone's upper box, again bearing two bells, was harder to access. A skeleton lock guarded entry from the curator, but not from Dick. He quickly picked through it. Unlike the previous three lids, which lifted entirely off, this one swung back like a door. The magneto mechanism remained obstructed, but something else riveted our attention. Fine wires ran inside the box to the lid's hinges, and then along the lid's inner surface to holes where it passed to the top (Figure 3). As Dick examined this wiring and discussed it with Debbie, they inferred its story. The hinged lid posed a particular problem to the phone's maker: how to run the electrical path from the apparatus inside the box to the bell's clapper on the swinging lid's outer surface? All of us marveled at the ingenious solution. The wiring path passed through the hinge (Figure 3). The hinge is part of the circuit!
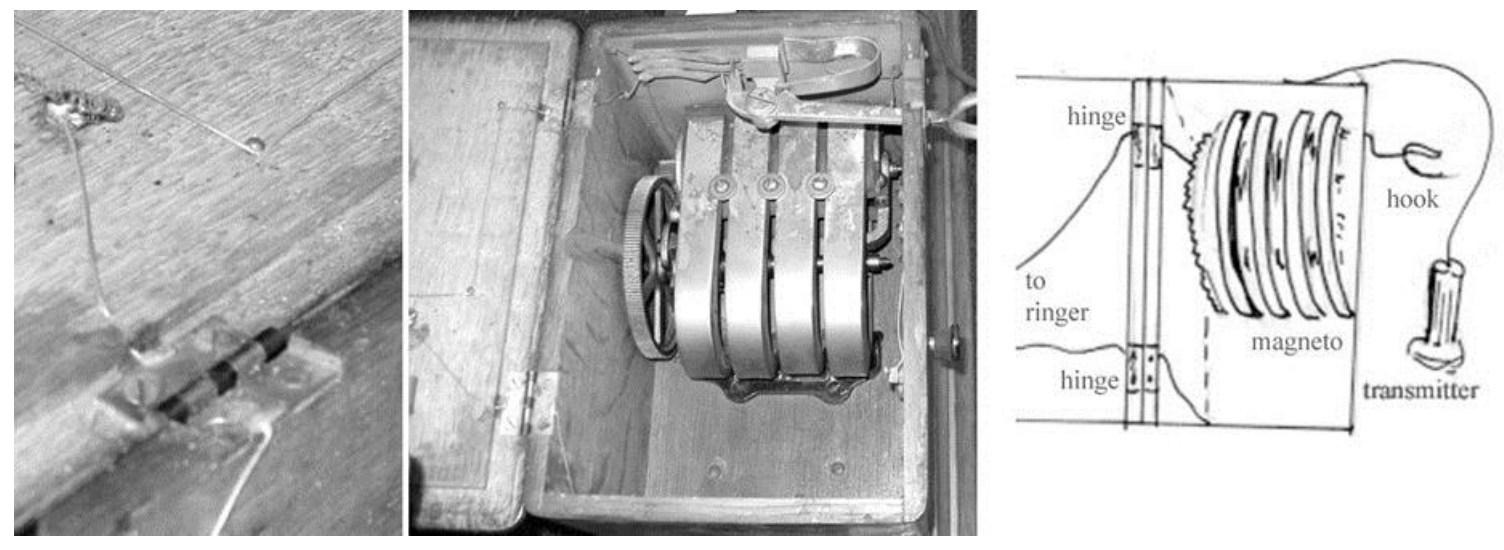

Fig. 3 Left: Wire soldered to either side of hinge; running along the lid it passes through a hole (top left) to the lid's outer surface. Middle: Inside of telephone box showing both hinges and magneto, telephone. Right: Diagram showing wiring path. (\#IN 857)

The insides of things could be startlingly provocative - or (like the broken porcelain) apparently irrelevant - to extending what we understood about the telephone's make-up. Inside and outside came to be seen as of a whole, where covering lids were permeable to electrical wiring and actions of crank and gearing. Getting to the insides of things was at the same time a way of reinterpreting their outsides. Just to open up each phone the curator and students had to innovate distinctive actions such as unscrewing a lid, releasing a crank, picking a lock.

In performing these actions, the learners came into direct relation with constraints faced by the maker and ingenuity in the design. Just as handling butter molds gave rise to "interleaved and interdependent" inferences about function, culture and history in a discussion among high school students (McKinney 2004, p. 177), a similar interrelatedness emerged in the responses of Dick and Kathleen to opening up telephones. For example, Kathleen's sense of how listeners in social interactions held the Gray phone differently to talk or to listen was productive for examining the three-position switch's electrical function, when Dick wondered if one position was for listening and another for talking. Similarly, analyzing the hinge involved Dick in taking stock not just of electrical connections, but also of the maker's need to seamlessly bridge the phone's concealed mechanism with its social exterior function.

The physical learning that engaged these students in opening things up and guessing their workings, was not confined to a single topic, such as telephone circuitry. Several weeks later, during a visit to the Burndy Library, curator Ben Weiss brought out a nineteenth century Voltaic pile. ${ }^{4}$ This had special interest: in a prior lab session we had made Voltaic cells from copper and zinc discs immersed in salt water. Handling the historical pile with white gloved hands, Dick and 
Kathleen lifted the discs near the top of the stack, and also at the bottom. Upper discs were looser, having been jostled a lot, whereas lower ones were more stable. Only by actually moving the discs, did Dick and Kathleen discover that the zincs and coppers were not separate pieces. They appeared to be separate, as in Volta's original paper (Volta 1800) and our laboratory reenactment. But instead, Dick and Kathleen discovered that each pair of zinc and copper discs was pressed together as one unit. Dick speculated that the paired discs were united in a coin press. $^{5}$

Seeing this, and realizing that pressing the metals together produces a contact superior to the loose discs of Volta and our lab assembly, Dick envisioned a new experiment. He wanted to file off the edges and bottom sides of pennies and pile them up with a moist separator, like Volta. ${ }^{6}$ Present-day US pennies, having copper plating over a zinc interior, contain a voltaic couple hidden within - if, like Dick, we imagine opening them up!

\section{Sound Made Visible}

Our daily environment is replete with sound, yet we seldom think about how sound is made and how it gets from place to place. Sound is often overlooked as a topic within science instruction. A survey of the teaching of sound across the past century, as represented in a prominent science teacher journal, found a dearth of references to sound in recent decades (McGinnis 1998). Developments in the science of sound, and historical analyses, were notably missing in all the practitioners' discussions about teaching sound.

This educational neglect of sound extended its reach into our small group. The first page of Kathleen's lab journal opens with the reflection:

At our first class meeting we learned the principles of sound transmission. Despite my limited background in physics, I truly enjoy understanding how things work. I knew nothing about the physics of sound before this class and thus learned a great deal. In class, we attached a speaker to a long, plastic clear tube. We broke off bits of Styrofoam and placed them in the tube so that we would be able to visualize the sound transmission. Because the particles weren't moving at first, we put a soda can at the end to prevent air from escaping. (Stevens, Feb. 10, 2005)

The speaker and tube apparatus that Kathleen wrote about was devised by Dick during a pre-class meeting that she couldn't attend. On that day, after looking over some materials -including speakers -- that I had assembled for class activities, Dick and I visited the physics lab supply as a reconnoiter to uncover other potentially useful items. Spying the long wide transparent tube in a corner, Dick remembered his previous homemade contraptions combining speakers with other materials and asked to borrow the tube. Back in the lab, Dick fitted a large speaker to one end of the tube and duct-taped it in place. He hooked it up to a frequency generator, dialed through different frequency ranges, and we listened to the changing sounds. It was Dick's idea that if we put something in the tube, it might react to the sound waves and "visualize the sound". Our time was up before we found a suitable material; Dick recommended something light like Styrofoam. ${ }^{7}$

When Kathleen joined us a week later, I introduced her to the student oscilloscope which she'd never used before. We looked at a wave from the function generator, talked about its ups and downs in time, and then contrasted this with the straight line showing when I hooked a D cell to the scope probe. Drawing on paper, Dick described sound to Kathleen as a back and forth that, being changed into electricity, could put a wave on the scope screen. 
I proposed reassembling the speaker and tube to test Dick's idea for visualizing sound. In our hands, we broke up a Styrofoam box that I brought in. After pouring Styrofoam bits so they coated the first third of the tube's length, Dick taped on the speaker to which we connected both the function generator and the oscilloscope leads. The tube hummed. We looked for motion in the Styrofoam, but all was still. Dick tried different settings and amplitudes on the frequency generator, and the audible sound varied in both pitch and loudness. To muffle the sound, we blocked the tube's far end.

Something stirred in the tube, but not everywhere. At some points along its length, we noticed slight agitation; in other areas, bits were jiggling almost everywhere! Kathleen and Dick looked intently along the tube to make out where motion changed to lack of motion (Figure 4). Kathleen moved her hands along the tube, feeling vibrations in some areas, not others. As Dick varied the frequencies, we identified one where the sound was loudest and the motions were quite evident, continually dancing even in a tube sheltered from air currents.

Trying to see what was going on in another way, Dick hooked my small microphone to the oscilloscope and moved the microphone back and forth along the side of the tube. For a long time, we watched its unsteady, varying signal on the oscilloscope screen. There were now two views at once: something to see both at the tube and on screen. Interpreting these views involved us in coordinating between what these showed at different positions along the tube and at different settings of the frequency generator. It was hard to make out places where (or even if) the microphone signal and the bits' motions were both greater.

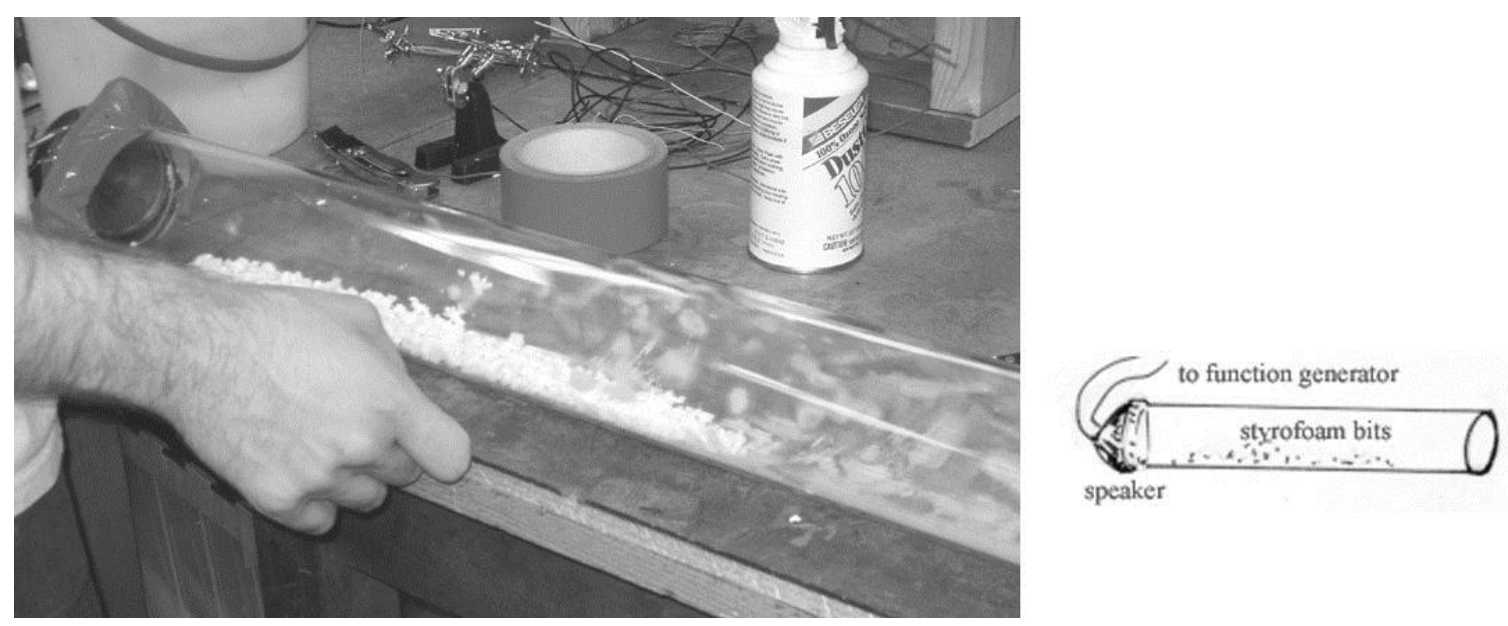

Fig. 4 Left: Speaker taped to clear tube filled with Styrofoam bits. Right: Diagram.

When I suggested breaking to write notes, no one wanted to stop. While Dick set about doing a calculation, Kathleen rang a tuning fork and I tried to pick up its sound with the microphone. Dick worked alone, first with frustration, eventually with assurance.

When Dick rejoined us, I asked him to share with Kathleen what he had been doing. Dick said he wanted to check our experiment against the relation between frequency, sound speed, and wavelength that he learned in college physics. He solved it for wavelength, which he interpreted as the distance between agitations in the tube. The estimate was way off. Then he looked up the topic in a physics book, found he had misremembered the speed of sound, and revised the wavelength to twice the distance between agitations. His recalculation came out on the order of dimensions in our tube. In the short time remaining, Dick resumed exploring the 
tube using only high frequencies (kilohertz). The bits no longer showed vigorous vibrations and he wondered what was different. ${ }^{8}$

The activity to make sound visible took off from Dick's previous experience with speakers. Ostensibly, it had to do with college physics. But to make this connection apply, Dick found himself reevaluating what he thought he knew from physics and about the tube set-up. Separate pieces of his science background became integrated in the process. For example, the numerical value of the speed of sound turned out to matter for something he wanted to check about apparatus he had constructed from tape, plastic tube, Styrofoam, and speaker. The equation between frequency and wavelength could be helpful only upon rethinking how the bits show wavelength. Weeks later, Dick resumed work with the tube, trying out different speakers, amplification, and a water layer along the tube - and again met up with confusing behavior.

In Kathleen's hands, the speaker-tube was a first opening to learning about sound not only audibly, but also through sensations of touch and sight, which she had not expected to relate to sound. In her journal, she wrote that after class she read in the physics book Dick had used, and lent to her, about sound waves, frequency and speed (Stevens, Feb. 10, 2005). Through (unassigned) reading, she acted to integrate what she was seeing and learning about sound in experimenting with the tube.

Many sessions later, we came back to these explorations, using tuning forks dating from MIT's nineteenth century origins. Historian David Pantalony and I found the apparatus coated in dust and oil in the working instructional collection of the Physics department. ${ }^{9}$ MIT's set of electromagnetically-driven tuning forks with mounts were made (and signed) by Rudolph Koenig $(1889$, p. 67) of Paris and Max Kohl (19--, p. 452-3) of Berlin, the premier acoustical instrument makers of the day (Pantalony 2002). This apparatus demonstrated wave vibration, beats, resonance, and Lissajous figures by optical means that could be projected large across darkened lecture halls. Faraday's successor at the Royal Institution, John Tyndall (1867), introduced these demonstrations into acoustics lectures, projecting three-foot high images of vibratory motion and the revolving, seemingly three-dimensional, Lissajous figures. The figures' beauty intrigued public science audiences of the day and their clarity in explicating sound ensured a role for them in physics instruction (Ganot 1863, Pickering 1873, Mayer 1878) until the advent of oscilloscopes in the early twentieth century (Turner 1996). Associated instructional exercises (Mayer 1878) asked students to construct drawings of waves, beats and Lissajous figures, for which MIT professor Edward Pickering (1869) devised a machine that moved paper on one axis and the pen perpendicularly. ${ }^{10}$

One week preliminary to using MIT's historical forks, Kathleen and I worked with an oscilloscope along with two frequency generators as inputs (although Dick was away both for this session and the following one, we met on three other occasions to explore and photograph the tuning forks). Starting with one waveform, I suggested to Kathleen that she try varying it with the frequency and amplitude dials on the first generator. Next, I attempted unsuccessfully to add a second waveform. Kathleen was curious and asked what might be going wrong. While redoing connections and exchanging probes, I described my questions and the checks I made of the wiring. Eventually I determined that the second frequency generator was nonfunctional. On replacing it by a third, two waves finally appeared on screen.

Kathleen adjusted one wave at its generator until the two waves matched. I put the oscilloscope at its XY setting. This setting added another way for her to look at the two waves by compositing them at right angles to each other. We saw a diagonal oval. Returning to the twowave display, I suggested that Kathleen stretch out one wave twice as long as the other. Then, on 
switching back to the XY display, the pattern showed from a wave to its double showed the figure-eight of the Lissajous figure for an octave. Going back and forth between the two settings, Kathleen made wave pairs differing in relative lengths and in their crosswise sum. We compared these to Lissajous illustrations in the readings (Turner 1996, Ganot 1863) which she read for the next time.

Historian David Pantalony came to class for the first ringing of MIT's Koenig and Kohl tuning forks in decades; Edgerton Center director James Bales joined us part-way through. Running the forks was an experiment for everyone. Aside from a preliminary trial with these instruments, only David had any previous experience with Koenig forks and their graphical effects. ${ }^{11}$

The historian described what he has learned about Koenig's research and construction of acoustical instruments. Together we examined the historical instruments, looking for details of the artisans' signatures and filing marks, and tracing out the workings of the electromagnetic drive. Then I asked Kathleen to activate the vertically mounted Koenig fork by turning a screw to close the gap on its contact breaker (Figure 5). Nothing happened; no one could say where the problem was. I discovered that one terminal of the car battery was unconnected, but even reconnection did not start the fork. As each of us tried turning the screw, we found it had overtightened. On backing off the screw, sparks brightened in its gap and the fork resounded loudly! Just setting it going involved setback, experiment and surprise.
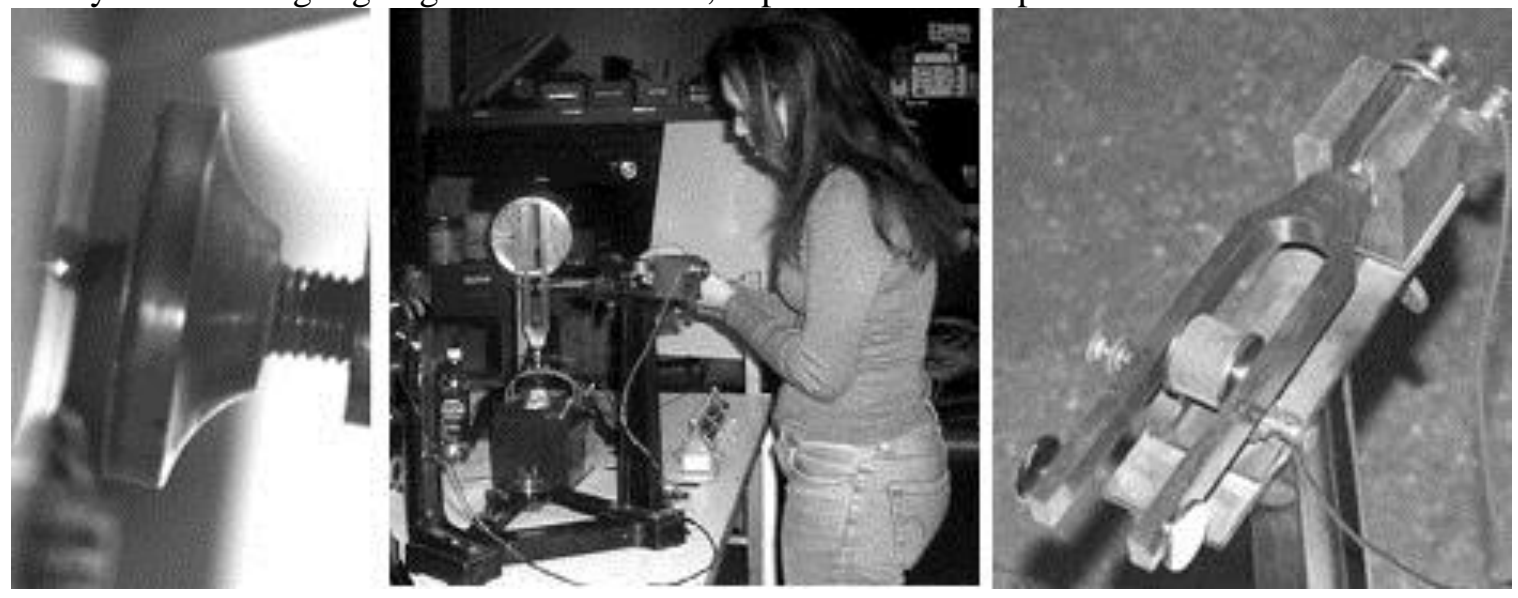

Fig. 5. Left: sparking of moving fork at its contact breaker screw. Middle: Kathleen adjusts the horizontal fork while the Lissajous figure 8 appears on the screen behind her. Right: The horizontally mounted Kohl tuning fork. Left and Right photos by Richard Whitney.

Kathleen and I worked in the dark to orient a laser (our light source, in place of the traditional lantern) until its beam fell onto a small mirror affixed to the vibrating fork's tine. Its bright reflected dot showed across the room. On happening to move our heads while watching it, we perceived a wave pattern. Again by turning a contact screw, Kathleen activated the vertical fork of the Kohl apparatus and more sound filled the room. We found that the laser had to be reoriented before its reflection off the Koenig forks' mirror would strike the mirror on the Kohl tuning fork. In seeking this alignment, I was trying to follow a diagram (Figure 6, Left) of Lissajous' method for showing beats. When we coordinated the laser beam with the two moving forks, its doubly reflected dot oscillated up and down, changing in the lengths of its excursions.

The effect was beautiful. At first the historian did not understand what he was seeing. He said he had never seen the beats before! He had not known this could be done with tuning 
forks. For Kathleen also, beats were new, never having come up explicitly in our previous work with sound or the oscilloscope.
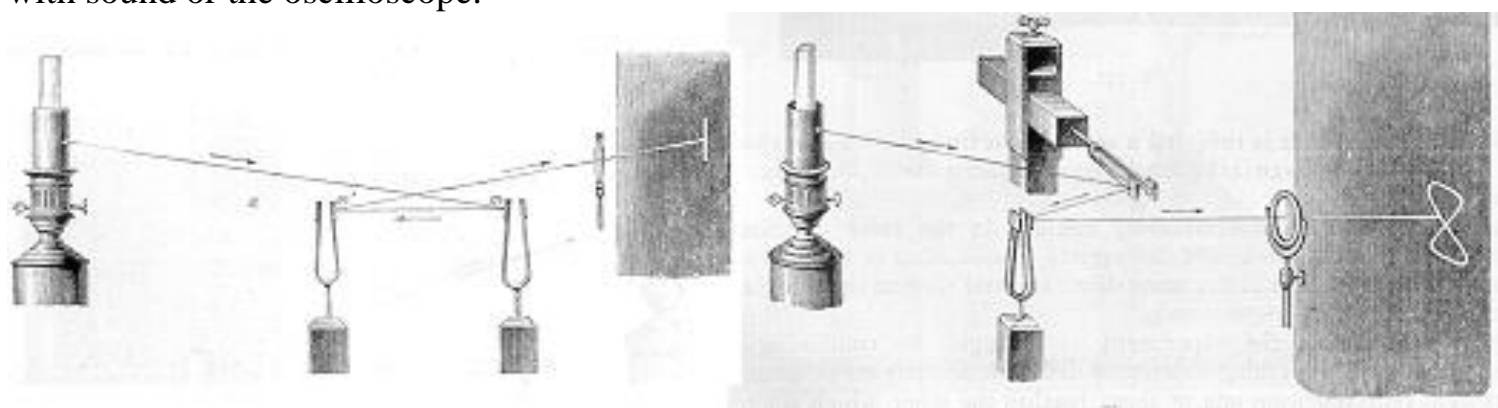

Fig. 6 Left: A light beam reflected from tuning forks mounted in parallel demonstrates beats. Right: When the forks are mounted to vibrate at right angles, the reflected beat executes Lissajous figures. [From Ganot 1863, Fig. 272 and 273.]

To attempt the Lissajous figures, we disconnected the Koenig fork and worked only with the Kohl apparatus having both vertical and horizontal mounted forks of frequencies an octave apart (Figure 6, Left). ${ }^{12}$ Kathleen turned the screw to start the horizontal Kohl fork (Figure 5). Again we had to reposition the laser so its beam reflected between mirrors on the two forks. At first, the pattern projected from these forks was very narrow. Exploring the apparatus we found it allowed for adjustments in the forks' position, in the spark screws, and in sliding a weight along one time. Surrounded by the singing octave sounds, we saw the bright figure 8 (Figure 7) widen and revolve upon our paper screen!

Once lab director Jim Bales joined us, we attempted to substitute into the apparatus forks bearing different frequency relations to each other. The first substitute didn't quite fit. Everyone participated making shims from playing cards and trying other adjustments. Jim called this activity "too much fun", likening it to Harold ('Doc') Edgerton's improvisational work. With the fix in, a new Lissajous pattern appeared (Figure 7) — along with its sound. More adjustments ensued to work in another substitute. David and Kathleen looked at how vibrations passed from fork to fork even when a fork was off. Staying beyond our ending time, Kathleen said it was our best class yet and wrote:

The shape of the figure we produced was a product of the two forks vibrations. The images were amazing. It was quite helpful and interesting to me to do the same experiment that we did [previously with oscilloscope] using less technology. (Stevens, April 14, 2005)
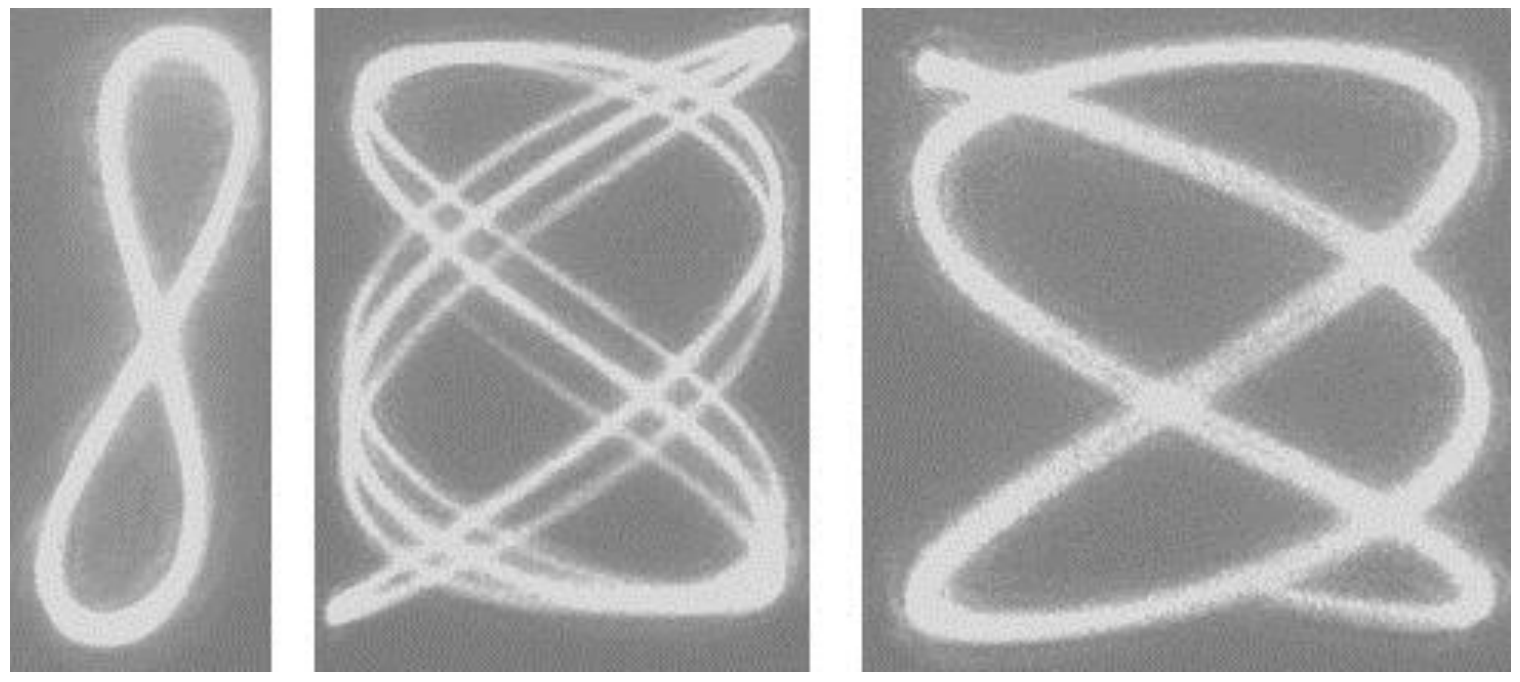
Fig. 7 Lissajous figures produced on a screen by a laser beam reflected from two crosswise tuning forks. Left: Tuning forks an octave apart $(128$ and $256 \mathrm{~Hz})$. Middle and Right: patterns from tuning forks at the interval of 3:5 (128 and 213Hz). Photos by Richard Whitney.

Kathleen's comment about technology reveals the relation she perceived between two composition methods. Adding waves in the form of crosswise electrical signals had something in common with using light to combine perpendicular vibrations of sound. Electricity and sound were somehow alike enough that the very same figure-eight could be made with either phenomenon. Observing these connections, as she did, could make a beginning for further explorations of waves, the oscillations giving rise to waves, and how these interface and sum in different media and modes of propagation.

Working with the historical tuning fork apparatus was almost like opening the oscilloscope up, letting us feel, hear, and see sounds and their combinations. Perhaps Kathleen's awareness that the forks' patterns, and those on the oscilloscope, make sense together, speaks to something left behind in much present-day science instruction. Mechanical techniques and apparatus for teaching sound are neglected - in this case being literally coated in dust - while their role is sometimes taken by simulations lacking physical extension. ${ }^{13}$

The Kohl apparatus extended into other dimensions the activity initiated with Dick's speaker-tube, to make sound visible as well as tactile and audible. With it, not just something about sound, but also interaction, became visible by the beam reflected off a second vibrator. That interaction showed differently when the forks were oriented parallel from when they were crosswise, and its fluctuating or revolving pattern disclosed discrepant timing between the two vibrations. And to get the apparatus going involved hooking up a car battery, fine-tuning the spark gap to electromagnetic coils, as well as hearing sound and positioning the light. Electricity, magnetism, sound and light integrated in the immersive experience of operating the forks in a dark room.

Relatedness among participants, as well as among phenomena, emerged during the experimenting with historical forks. Brought together by the first reactivation of the apparatus, a community arose where no one knew quite what to expect, everyone added to what happened, and each experienced surprise and connection in different ways. Experimenting where the uncertainties and improvisations are real and shared, is pedagogical in the sense that teaching and learning arises in, and consists of, doing this work. The pedagogy transpires in actions and interactions taking place among participants and phenomena.

\section{Orientation Matters}

Learning by working with things brings out other observations that might not arise in an environment where things are represented only by abstract or simulated stand-ins. One of these involves the ways an object's material properties and structural make-up play an essential role in whether or not it exhibits specific phenomena (Baird 2004). A magnet magnetizes needles, not toothpicks; a dropped paper wad falls faster than a paper sheet. It may be safer to give school children toothpicks, than needles, but toothpicks cannot be made to attract and repel like little magnets. It may be quicker to drop a paper wad, but the local air currents will be more apparent in the fall of a paper sheet.

A cognate observation emerged as the students took things in their hands while exploring. Sometimes there was a mismatch between the way an object is handled or designed and its natural behavior. This mismatch was most evident for me, as the teacher, in experiments where the orientation of something mattered to the effect under investigation. The way that came most 
readily to hand, for placing or using an object, sometimes was nearly orthogonal to the orientation that best showed forth the physical effect.

Orthogonality matters in doing the Lissajous activities. Both the Kohl tuning fork apparatus and the oscilloscope XY setting were designed to put vibrations at right angles to each other. However, with other experimental materials that we used, no such alignment guide was present. Then, the students' exploring involved dealing with physical behaviors that only showed up in certain relative orientations of the materials - which proved not to be the way of holding those items that came readiest to hand. Below I follow Kathleen's use of magnetic compasses to explore conducting wires. The facility of keeping wire and magnetic compass coplanar masked detection of the electromagnetic effect. Dick met up with similar issues when producing rainbows from sunlight striking prisms, where some prism orientations were easier to set up than others.

Early on, we set out to redo Oersted's (1820) finding that electricity in wires affects magnetic compasses. As an assignment at home, Kathleen had already lit bulbs by twisting their wires and contacting a $D$ cell battery. Now, to get a wire securely connected across a battery holder, she learned a new connection method:

One exciting part of this lab for me was soddering the wires to secure them together. (Stevens, March 3, 2005)

Melting solder into her hand-made joint was an act of meaningful learning from the materials. Before this Kathleen had never dealt with metal hot enough to liquefy. Making this one joint gave her a personal experience from which to interpret an 1830s magnet soldered by Joseph Henry, which we saw the following week in the Burndy Library. ${ }^{14}$

Whereas the soldering iron's heat could be felt in all directions around, the connected wire's magnetism was different, since our bodies do not sense it. As Kathleen moved a small compass near her soldered conducting wire, an observer could tell her lack of experience with magnetic phenomena. Dick came over and said "do you want me to show you the right hand rule?" Kathleen asked what that was, and I suggested letting her do more with the compass. Reframing the activity to encourage her to gain experience with magnets and compasses, I brought over a large permanent horseshoe magnet.

Seeing Kathleen try the compass only along the magnet's legs, Dick and I realized that the magnet's gap had not yet emerged for her as an interesting area. We filled a clear box with magnetite sand and taped it shut. As Kathleen held it near the magnet (Figure 8, left), the sand inside leapt into dense patterns around the gap. Dick pulled up a magnetic field lines diagram on his laptop. Kathleen wanted to know what made a magnet strong. Dick arranged headed nails all the same way to model a good magnet and jumbled them for a poor one. Kathleen began viewing compass needles as telling something distinctive about direction, for she wrote: ...we were able to determine the direction of the magnet current by noting the direction of the compass needle when the compasses were placed at many locations .... 

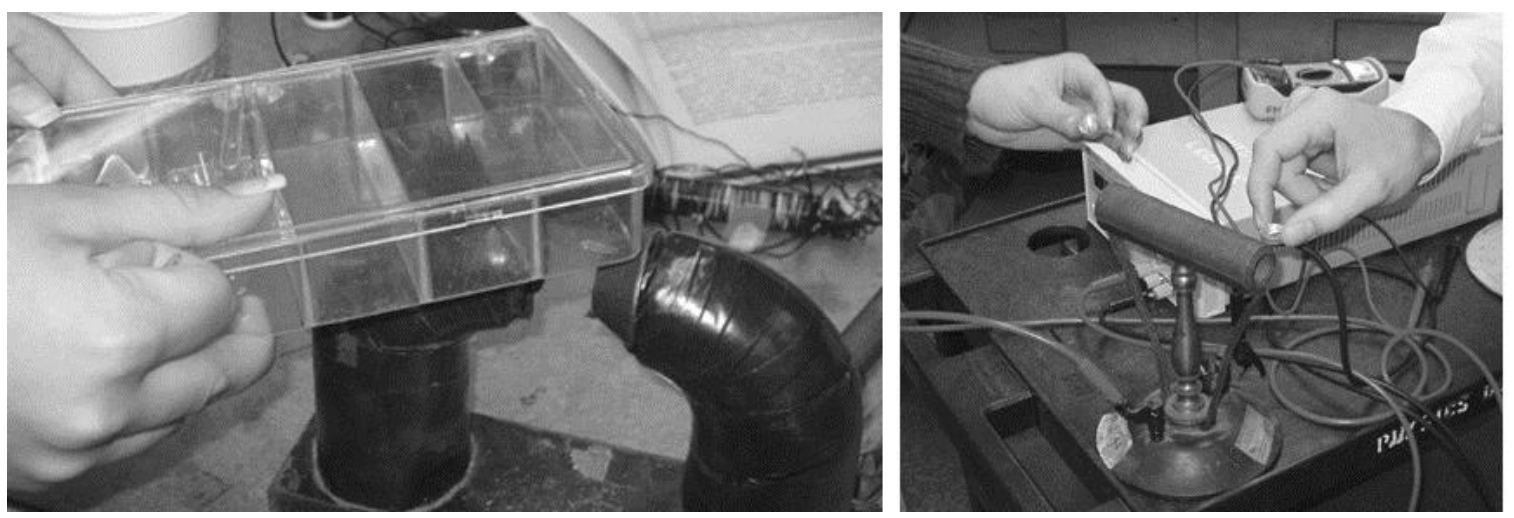

Fig. 8. Left: Kathleen holds clear container of magnetic sand over magnet gap. Right: Kathleen (left) and Dick (right) use compasses to explore an electromagnetic coil.

To resume with electromagnetism, I introduced a hollow historical coil run off a power supply. ${ }^{15}$ The set-up disturbed Dick: the coil's solder joint looked messy, the low voltage being metered with the operating coil was unfamiliar, and a needle failed to be affected by it (that needle was later proven nonfunctional). Checking things over and finding the coil operating properly, I encouraged the students to try again. Kathleen and Dick explored the coil's sides, ends, and even its interior first with compasses, then with metal rods and attracted paperclips (Figure 8, right). Kathleen described what this showed:

From the readings and our experiments I learned of many of the properties of electromagnets ...strongest at the ends...weaker toward the side of the magnet. (Stevens, March 3, 2005).

Dick was away the next time when Kathleen and I went back to looking at a conducting wire with a compass. To start, I selected a paragraph from 1820 to read about Schweigger's looping of a wire to 'double' its effect on the compass (Chipman 1966). ${ }^{16}$ It wasn't clear to Kathleen how to do what Schweigger described. Seeing it had to do with wire bent around the compass, she wound the wire in the compass' horizontal plane, like a ring around its outer rim (Figure 9). Due to the compass' circular shape, this loop was convenient to make. However the arrangement put the direction of the loop's magnetic field perpendicular to the plane in which the compass is responsive. The wire loop did not affect the compass.

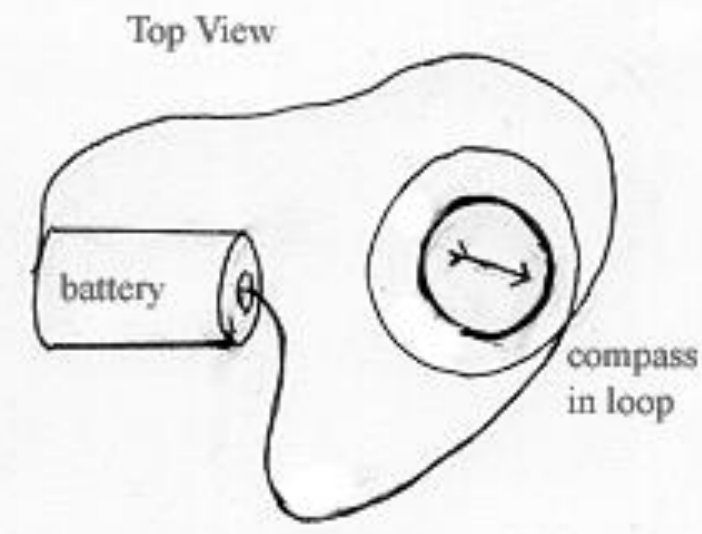

\section{Side View}

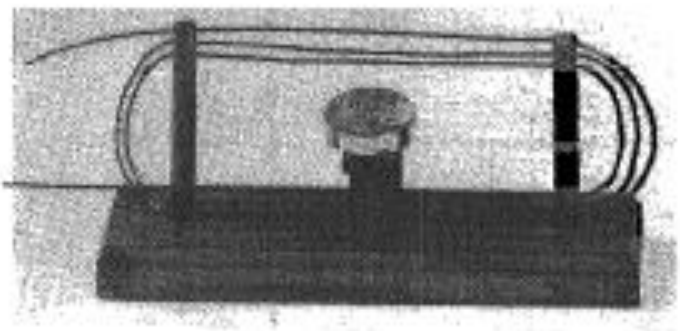

Fig. 9 Left: Top view diagram of Kathleen's placement of a magnetic compass in a current-bearing loop. Right: Model of Schweigger's loop around a compass, from Chipman 1966. 
Kathleen saw that her experiment disagreed with Schweigger's claim that looping the wire improved its effect on the compass. Schweigger also wrote that what the compass did depended on whether it was under or over the wire. Kathleen wasn't seeing this either. To encourage her to explore more possibilities, I asked Kathleen if there might be other ways of moving the compass and making up the loop. Nothing she tried was productive for seeing the effect.

Sensing her experimenting had stalled, I initiated a pause for us to talk. Kathleen said she was curious about all the ways people had found for showing how much electricity goes in wires. I described shocks, chemical decomposition, and arc lighting. Then we looked at early galvanometers illustrated in the reading (Figure 9, Chipman 1966). Kathleen immediately noticed that with these galvanometers, the wire loop was oriented different in relation to the compass, than what she had tried.

The historical texts mention the positions of wire and compass, but these descriptions stand out only for a reader attuned to look for them. For example, Oersted (1820) referenced the compass needle's deflection to the 'magnetic meridian', outdated language for Earth's northsouth direction. To expand this context, I set several compasses out on the table. We lay a wire on top of one, along the needle's north-south axis, and watched the needle when the battery connected the wire (Figure 10). Kathleen had the idea to also put the wire under the compass. At first, Kathleen observed only that the needle turned. She made no distinction between the two cases. On deliberately and repeatedly placing the compass over, then under, the wire, and connecting the battery into the circuit, she discerned the needle's opposite deflections. This had not been apparent previously, when she had moved the compass around the wire in her hands. Now she wondered if the needle turned more one way, or the other. She wanted to go on with this investigation at our next meeting.
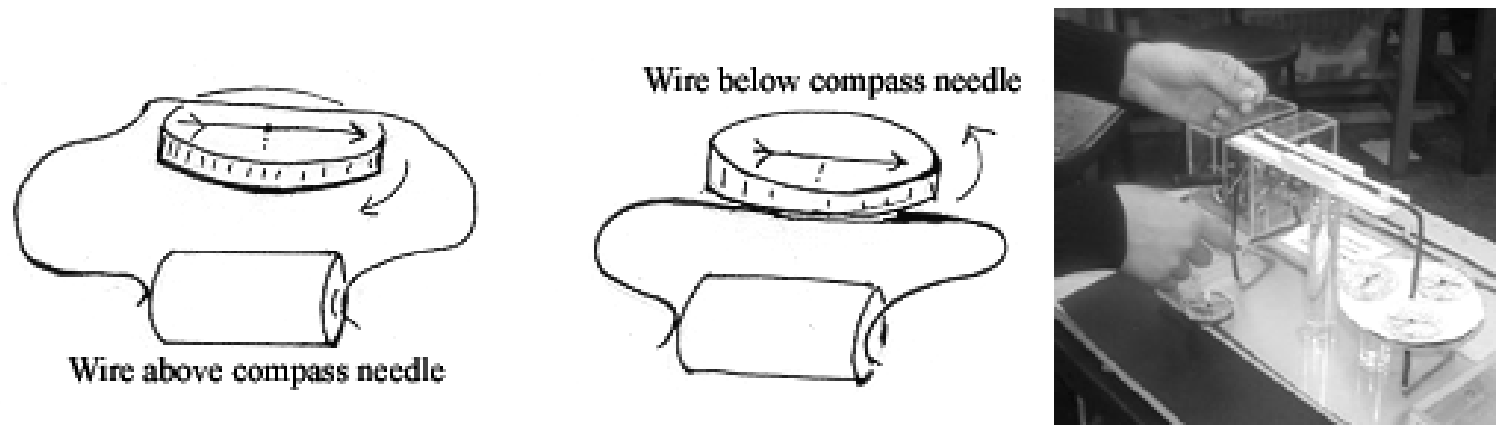

Fig. 10 Left: Conducting wire above compass needle. Middle: Wire below needle. When current is on, the needle deflects by 90 degrees, in opposite sense in the two cases. Right: Kathleen explores magnetism around demonstration conducting wire provided with surfaces to place the compass.

The following week, I borrowed a lecture demonstration apparatus whose thick conductor, powered by a car battery, was bent in a vertical loop and provided with built-in mounts for placing compasses above, below, and around it (Figure 10 right). ${ }^{17}$ I suspected this apparatus, designed to facilitate positions of the compass that are difficult to arrange on a flat table, could expand Kathleen's experimental options. Switching the circuit many times, Kathleen was now seeing what she had unsuccessfully sought before: the reversal in the needle's response between its placement below, and above, the conductor. This reversal correlates with our readings from Oersted and Schweigger, that the needle goes "in an opposite direction" when displaced from above the wire, to below it (Oersted 1820, 275). In Oersted's synthesis, the reversals were due to "the nature of a circle... motions in opposite parts should have an opposite 
direction" (p. 276). I was unsure whether Kathleen perceived these reversals as instances of magnetism circulating about the conductor.

To go further, I proposed another passage by Schweigger (1834) illustrated with a diagram of his double loop and compass. Kathleen read it carefully. Following the diagram (Figure 11, left), she crossed a wire over itself to form a double loop completed by a small battery. Again, the most convenient arrangement of these materials obscured the effect. The wire loops rested flat on the table. Kathleen moved the compass from loop to loop in the same horizontal plane (Figure 11, middle). The needle gave no response.
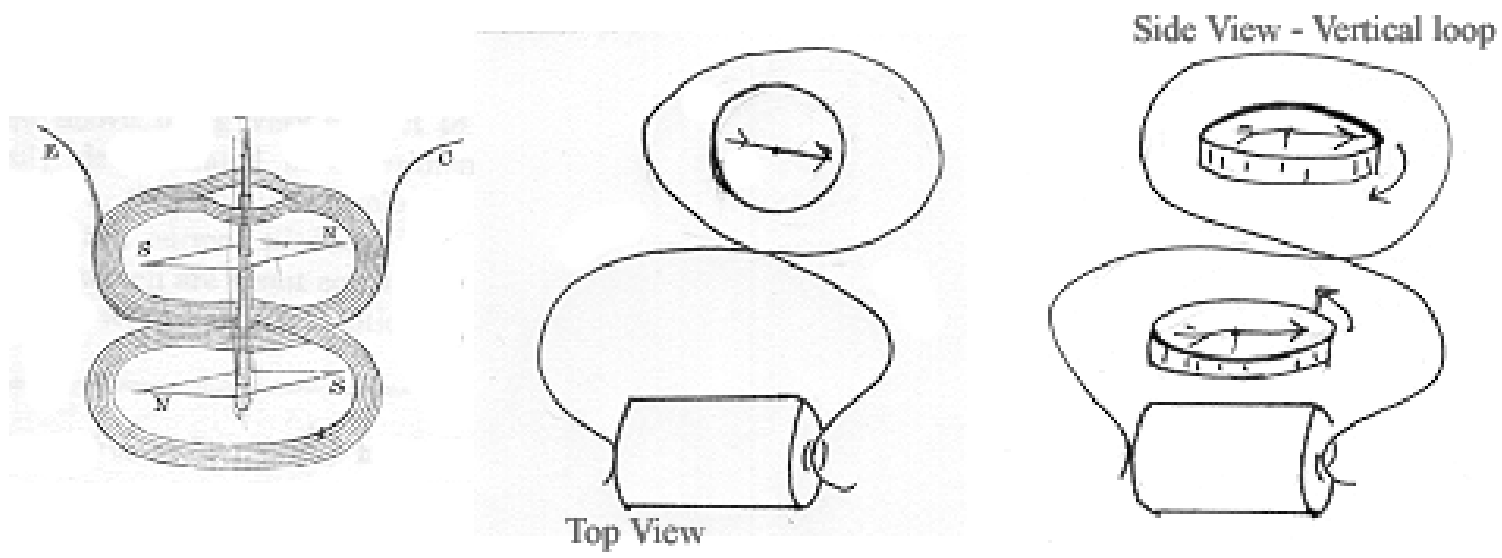

Fig. 11 Left: Schweigger's drawing of a vertical double loop with oppositely turning compasses (1834). Middle: Top view of coplanar double loop and compass. Left: Side view of vertical double loop where compass needle turns oppositely.

I suggested comparing the handmade loop with the demonstration setup. Kathleen switched the demonstration loop on, but registered no difference from her own. Returning to her loop, she again restrained the compass to the loops' plane. I suggested that she move the compass in the identical sense around the demonstration loop, to what she had done with her own loop. Doing this, she found the compass had to be turned out of the plane of the loop, before it showed a magnetic response. On going back to her loop, the table, while handy before, was now an impediment. Instead, we held the loops vertically in the air. Kathleen placed the compass in each loop (Figure 11, right), and saw the needle reversing!

Exploring a conductor's magnetism involved Kathleen in iterating among historical readings, diagrams, demonstration apparatus, and her own looped and soldered wire. Unlike the soldering iron's radiating heat, the electromagnetic behavior she researched was insensible and unintuitive. This inherent complexity was obscured by constructed materials that were easiest used in ways that nullified the effect without assisting in its disclosure. The circular magnetism around a wire was also "difficult to comprehend" for historical figures (Faraday 1821, p. 199, Cavicchi 2003). Through their examples, together with her perseverance, Kathleen made out for herself magnetism going circumferentially about an electric wire. She identified with historical accounts in writing that week:

Like Oersted described, the needle deflections varied with the relative position of the wire..."From these preceding facts," he writes, "we may likewise collect that this conflict performs circles" (Stevens, April 13, 2005)

Weeks before when Kathleen first ran a compass alongside her soldered conducting wire, Oersted's text had little meaning for her. Then for her, there was "conflict" between what the 
compass showed and what Oersted and Schweigger described. More experiences with the compass, along with her efforts to make sense of the different sources of magnetism and historical observations that I introduced, developed her awareness of how relative orientation matters in three dimensional space.

\section{Sense of History}

As a teacher interweaving historical experiences into labs with students today, sometimes I wondered, where is the history? When no one had time to do readings, or a historical observation did not match what we saw, or a student viewed something in the light of what is known now but not then, the history could seem remote. Eventually I learned that for the students, history did not rest on specifics, dates, or even ideas. The students formed their own sense of history through connections and differences they observed between historical materials and activities, and things of their everyday world. Just as with the phenomena, where sound, electricity, magnetism and light became interrelated, history also permeated our activities with the sense that someone before us had tried the experiments.

This quality of retracing a path tried by someone else in history became most apparent near the term's end when we followed a seventeenth century text to redo a chemistry experiment. ${ }^{18}$ Perhaps for the first time in centuries, we attempted to redo Wilhelm Homberg's (1693) ${ }^{19}$ procedure for smelting two compounds. It took him by surprise when the reaction's product gave off a luminous glow in the dark while he pounded it in a pestle (for another purpose). He recorded that his material flashed more, "beaucoup plus d'éclat" (Homberg 1693, 448), than sugar and other phosphorescent materials then known. Homberg's description of the light, along with his surprise, intrigued us; we shared a desire to see that luminous flash. The only way to learn more about what he experienced in the dark, was by smelting such a material ourselves. The uncertainty of interpreting a historical text took on immediacy through its role as our guide (along with a chemist's advice) to what he did and saw.

Questions abounded as Dick and Kathleen worked with the chemicals. How much of the two reactants, ammonium chloride and calcium oxide (quick lime slaked in air), should Kathleen weigh out? When were these powders well enough mixed? How high and close should the flame be to the crucible? What made our crucible break?!? How long would the smelting take; how hot did it need to get? Dick tended the crucible (a replacement) by watching, stirring, turning up the torch heat and by checking Homberg's report. He concurred with Homberg on many counts: the powders became molten, ammonia was outgassed, and the resulting material had an enamel surface with a propensity for absorbing water. However he had not seen the melt puff up or inflate in the crucible as Homberg described.

Was the smelting completed? Had we concocted Homberg's "nouveau phosphore"? Like Homberg, we dipped metal rods into the melt, and spread its white enamel on tile. The usual end of our class had elapsed long before, but Dick and Kathleen stayed on. We took the enameled rods to the darkroom, struck them on the table and hit them with a hammer. No one saw any light. Kathleen expressed our dismay:

I was disappointed that we may have made a mistake in our experiment. (Stevens April 27, 2005)

As a comparison check and back-up (in case our experiment did not work), I had on hand some wintergreen candy lifesavers which also exhibit the effect of triboluminescence. ${ }^{20}$ Opening the pack, Kathleen recalled a commercial jingle about lifesaver sparks in your teeth. She crushed them in her teeth - keeping her mouth open so we could look in -- and on top of a strip of high speed film. For just a moment, whitish light flashed! Kathleen and Dick smashed Homberg's 
enamel on another film. On developing these films, the lifesaver strip was speckled where light exposed it. Our enamel strip showed two tiny dots (Figure 12). Perhaps the new substance was not a failure! This was still in doubt when class ended, but I stayed on. Practice advanced the effect into visibility:

I was excited to hear that Elizabeth saw a white blue flash of light. (Stevens April 27, 2005)
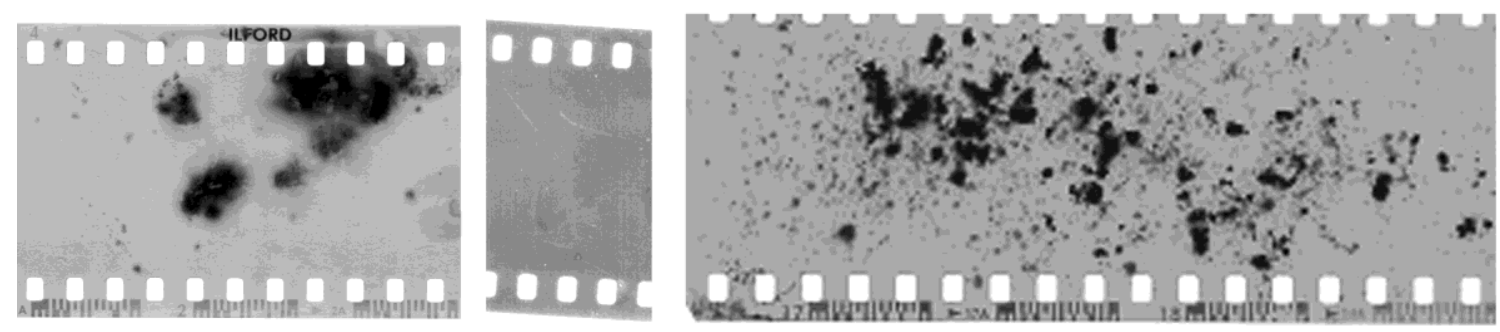

Fig. 12 Left: Film strip with wintergreen lifesaver crushed on it. Middle: Film strip with Homberg's material crushed, done during class. Right: Film strip with crushed Homberg material, done later.

The experiment evolved as we went back and forth between history and our present lab work. We repeatedly checked Homberg's text against the hot gooey stuff in the crucible. The discrepancies between what he wrote and what we saw came into relief, as did the places where Homberg was vague or nonspecific. Dick and Kathleen looked closely, and wondered about everything and anything that could matter to the reaction. The historical text gave further grounds for uncertainty; in it Homberg suspected that the quick lime produced in some areas might differ from that made elsewhere. Dick asked if our present-day commercially produced calcium oxide might lack some kind of local impurity that may have enhanced the behavior of Homberg's. As suspense intensified, the students became aware of clues and gaps lying between what we observed, and the original experiment.

Redoing the experiment brought not just heat and chemicals into its crucible, but emotions too: confusion, disappointment, excitement. History, the science phenomena and students' learning melded like the powders, bringing sparkle into experience. This is present in Kathleen's reflection on her "favorite experiment":

It was very hands-on and combined the principles of Physics and Chemistry. It was especially interesting to me because Homberg performed this experiment so long ago. (Stevens May 12 2005)

\section{Conclusion}

In experimenting with effects from historical science, Kathleen and Dick were dealing with materials and phenomena that did not behave quite as they expected. Much of their "guesswork" in devising ways to proceed went on with their hands: opening a lid, turning a dial or spark-gap screw, moving a compass, hammering on candy. On performing these actions, the apparatus gave them feedback: a magnet was inside; sparks and sound started; a compass needle moved; light darkened a film. When nothing happened, this was feedback too. Either way, the material response to an action of the learner posed something more to do, change, look for or ask in the next experimental trial, laying ground for the next action by the learner.

Taking part in historical experiments extended what the learners were able to do with their hands and with the materials, as well as what was there to observe and consider. These actions put the students in relation to those of historical investigators who also developed science understandings through experimental action with materials (Cavicchi 2006, Baird 2004, Gooding 
1990, Tweney 2006). Arguing that work with materials contributes to knowledge, Baird analyzes how scientific instruments 'bear' knowledge. For example, knowledge lies in an instrument's operative production of phenomena, such as the magnetic circulation arising around a conducting wire, and in means for interacting with these phenomena, such as magnetic compasses placed around the conducting wire. Through what they did with historical instruments and materials, Kathleen and Dick were engaging with material knowledge, such as Baird describes. Both the materials, and their actions, such as soldering wire across the battery, or moving the compass around that conducting wire, were authentic in keeping phenomena integrated with the relationships that are operative to the scientific effects. For example, sound did not fragment from the electromagnetic coils involved in making it and magnetism did not fragment from the spatial dimensionality where it was expressed, or from the electric current engendering it.

The learners' actions met with responses from sources other than materials and apparatus, including each other. For example, Dick introduced techniques from his machining background (when interpreting the oval hole in the telephone gear), as well as explanations of sound from college physics. These expressions encouraged Kathleen to watch attentively while Dick worked with tools, or to read something about the science he had studied. Reciprocally, Kathleen's curiosity - unhindered by preconceived expectations about what would happen - often interested Dick to the point where he brought materials for her to see. Once he hauled in a weighty neonsign transformer whose white glowing arc shattered the air; he said this was to show Kathleen what electricity really is. Their responses to each other integrated personal interest along with their differing ways of involvement in the subject matter.

As their teacher, I too responded. By looking closely at what was going on in their experiment, I noticed, for example, when Dick began trying only high frequencies with the speaker tube. In this way I realized that something had changed in how he understood this experiment, and checked my inference by asking him about it later. I intervened in their experiment sometimes to check whether an apparatus was nonfunctional, such as when Dick doubted that the Davis electromagnetic coil was actually running. Through doing this, the apparatus could often be restored to them for more exploration, and they also saw a practice of testing and checks. I often asked the students if there might be other ways to try an activity; as when Kathleen placed the compass in the same horizontal plane as the conducting loop. In this way I encouraged them to consider alternatives and widen the space of their observations and activities. Similarly, I sought to extend their opportunities for experience and inference by introducing instruments, materials, readings, field trips and other people such as historian David Pantalony. With these responses, I worked to sustain their experimenting, to keep it going to new places, and to revisit areas (like the magnetism of conducting wires) where I observed that something more remained for them to work out. The actions of teaching were experimental and uncertain "guesswork" for me, as were the students' actions in exploring the materials.

Because teaching was interactive, it could also be integrative, just as learning was for the students. For example, in putting aside what I had planned for the first session, starting instead with Dick's newly constructed speaker-tube, I precipitated activities whose unfolding would be new to me too. Making sound visible with the tube encompassed such varied teaching actions as finding Styrofoam to test in it; making time for Kathleen to practice with the oscilloscope and for Dick to do his calculation; observing closely the frequencies Dick tested and those he omitted; and arranging subsequent experiences (with oscilloscope and tuning forks) by which they might encounter more ways of visualizing sound. I was not performing separate teaching tasks, but integrating whatever I observed and did with the students, their investigation, and the materials. This kind of integrative experience is not possible unless the teacher is willing to observe and tune the learning experience as it is taking place. 
The context of history supported the interrelations among phenomena and participation that evolved in our "guesswork" actions with materials, artifacts, experiments and readings. With museum curator Debbie Douglas, we participated in the surprise of recognizing the longforgotten ingenuity of a hinge integrated into the telephone circuit. Through her effort to make sense of Schweigger's text and diagram, Kathleen stretched the bounds of the experiment to try new orientations of wire and compass, and think about what those showed. The beauty of Lissajous' intricate tracings of light revolving in a dark room resonant with sound, and of phosphorescence emitted upon fracturing homemade compounds, aroused curiosity and wonder from Kathleen and Dick so much that no one wanted to leave.

There is a stark contrast between historical and textbook accounts of the same science. In historical accounts, the phenomena are still enmeshed with the original explorers' actions, thought and emotions. Instructional treatments and advancements in technology (composed subsequent to the history) fragment phenomena and calcify the boundaries between experimenter and phenomena, to distance learners from materials (see Venville et al. 2000, 2002). The pedagogical actions identified here (opening something up, making sound visible, orienting materials, reflecting on history) recover some of the interrelatedness in historical accounts along with the history, reintroducing the wonder of directly interacting with physical phenomena into the world of students today.

For example, opening something up took away some of the blinders. Inside an old telephone, the wiring paths and electromagnetic motions can be traced by eye, guessed at, and checked by experiment. This activity is not practical today, where the electrical components inside are so compact and inscrutable that they are like another lid on the box. Engagement with historical instruments and experiments pries off some of those lids. For Kathleen, taking apart 1870 s phones gave her some grounding for appreciating cell phones, just as the historical tuning forks echoed the oscilloscope's Lissajous figures. Something obscured by layers of technology becomes potentially knowable through its origins, as Kathleen observed:

...this class was like building a foundation and learning from the bottom up. For example, since I now know how sound is transmitted and the inner-workings of historical telephones, I can more fully understand how modern day telephones work. Learning science history helps you to better understand technology and why it developed. (Stevens May 12, 2005)

By tapping into the relatedness of physical things and experiences, students' explorations among historical materials and historically observed phenomena are generative for further and ongoing work in science. One observation gives rise to others, all retaining connections through the actions and queries of participants. Context matters, yet can be critiqued too, as when Dick asked if commercial calcium oxide could substitute for Homberg's quick lime. Whenever students attend carefully to an observation, whether it is their own, or one from the past, unexpected questions arise. In following up on these questions, students may begin to see alternatives, differing perspectives, ambiguities and connections. Historical materials offer a special capacity for opening science curriculum to encourage this kind of student participation, where "pat answers" can be seen to founder, and the "guesswork" of pushing an experimental activity further becomes exciting and productive. By being watchful for these openings, as teachers, we become receptive to supporting our students' active curiosity about the world and its interrelatedness.

\section{ACKNOWLEDGMENT}

I thank Kathleen Stevens and Richard Whitney for working observantly together in the lab and with history. James Bales created the possibility for this teaching experiment and enriched it 
with many ideas. Lab meetings and activities were supported by MIT's Edgerton Center staff including Tony Caloggero, Amy Fitzgerald, Sandra Lipnoski, Edward Moriarty, Eileen Huang. Markos Hankin, Bill Sanford and Patrick Ragsdale shared lab experience and physics apparatus; Krystyn Van Vliet and Laura Trudel helped with chemistry materials. Deborah Douglas, Ben Weiss and Gil Cooke gave meaning to our visits in historical collections at the MIT Museum, Burndy Library, and MBTA Roslindale power substation. We were advised by David Pantalony for the tuning fork experiment, by Lawrence Principe for Homberg's reaction, by Howard Fischer for Newton's prisms, and Thomas Settle for Galileo's work. George Smith and Bonnie Edwards of the Dibner Institute sponsored the course development. Constance Barsky discussed Aron's pedagogical work and history with me. This manuscript benefited from comments by James Bales, Alain Bernard, Angela Kimberk, Alythea McKinney, David Pantalony, Roger Sherman and the reviewers. I thank the organizers of the Leeds IHPST 8 Conference for the opportunity to present this paper on July 17, 2005. For her mentoring in explorative teaching, I thank Eleanor Duckworth; for the thoughtfulness in their teaching with materials and history, I thank Fiona McDonnell, Bonnie Tai, Lisa Schneier, Petra Lucht, Peter Heering, Claryce Evans, Wolfgang Rueckner, Susan Collins, Ryan Tweney. Alva Couch, Alanna Connors, Phil and Roy Veatch are co-experimenters. This work is dedicated to the memory of Philip Morrison, who inspired it and delighted in hearing about each exploration made by Kathleen and Dick.

\section{REFERENCES}

Allchin, D., et al.: 1999, 'History of Science - With Labs', Science and Education 8, 619-632. Arons, A. B.: 1982, 'Phenomenology and logical reasoning in introductory physics courses', American Journal of Physics 50(1), 13-19.

Bagno, E. et al: 2000, 'From fragmented knowledge to a knowledge structure: Linking the domains of mechanics and electromagnetism', Physics Education Research, American Journal of Physics Supplement 68, S16-S26.

Baird, D.: 2004, Thing Knowledge: A Philosophy of Scientific Instruments, University of California, Berkeley.

Bell, A. 1875-6. Notebook by Alexander Graham Bell, from 1875 to 1876, The Alexander Graham Bell Family Papers, Library of Congress, Washington DC: http://memory.loc.gov/cgi-bin/ampage

Carman, R. A.: 1955, 'Kundt Tube Dust Striations', American Journal of Physics 23, 505-507.

Cavicchi, E.: 2006, 'Faraday and Piaget: Experimenting in Relation with the World', Perspectives on Science, 14, in press.

Cavicchi, E.: 2005, Weekly Journal and Photos.

Cavicchi, E.: 2003, 'Experiences with the magnetism of conducting loops: Historical instruments, experimental replications, and productive confusions', American Journal of Physics 71, 156-167.

Cavicchi, E.: 1999, 'Experimenting with Wires, Batteries, Bulbs and the Induction Coil: Narratives of Teaching and Learning Physics in the Electrical Investigations of Laura, David, Jamie, Myself and the Nineteenth Century Experimenters - Our Developments and Instruments', Dissertation, Harvard University, Cambridge MA.

Challoner, J.: 1995, The visual dictionary of physics, Dorling Kindersley, Boston MA.

Chipman, R. A.: 1966, 'The Earliest Electromagnetic Instruments', U S National Museum Bulletin 240, 123-136.

Corn, J.: 'Object Lessons/Object Myths? What Historians of Technology Learn from Things', in Kingery, W. D. ed., Learning from Things: Method and Theory of Material Culture Studies, Smithsonian, Washington DC, 35-54.

Crawford, E.: 1993, 'A critique of curriculum reform: using history to develop thinking', Physics Education 28, 204-208. 
Conant, J. B. (ed.): 1957, Harvard Case Histories in Experimental Science, Harvard University Press, Cambridge MA.

Crowell, A.D.: 1981, 'Motion of the earth as viewed from the moon and the Y-suspended Pendulum', American Journal of Physics, 49 (5), 452-454.

Davis D.: 1842 (1857). Manual of Magnetism, Palmer and Hall, Boston MA.

Devons, S. and Hartmann, L.: 1970, 'A History-of-Physics Laboratory', Physics Today 23 (2), 44-49.

Duckworth, E.: 2005, "Critical Exploration in the Classroom", The New Educator, 1(4), 257-272.

Duckworth, E.: 2001, "Tell Me More”: Listening to Learners Explain, Teachers College Press, NY.

Duckworth, E.: 1999, 'Address', unpublished transcript, Institute on Teaching and Learning (with Eleanor Duckworth), Miquon School, Conshohocken PA, January 22-23, 1999.

Duckworth, E.: 1991, 'Twenty-Four, Forty-Two and I Love You: Keeping it Complex', in Duckworth, E., "The Having of Wonderful Ideas" and Other Essays on Teaching and Learning, Teachers College Press, NY 1987/1996.

Fagen, M. D., ed.: 1975, A History of Engineering and Science in the Bell System, Early Years (1875-1925), 1, Bell Telephone Laboratories, Inc., NY.

Faraday, M.: 1821, 'Historical Sketch of Electro-magnetism', Annals of Philosophy 18, 195-200.

Ganot, A.: 1863, Ganot's Elementary Treatise on Physics Experimental and Applied, E. Atkinson, trans., ed., William Wood, NY, 1899.

Gooding, D.: 1990, Experiment and the Making of Meaning: Human Agency in Scientific Observation and Experiment, Kluwer Academic Pub., Dordrecht.

Gorman, M. and Kirby Robinson, J.: 1998, 'Using History to Teach Invention and Design: The Case of the Telephone', Science and Education 7, 173-201.

Hammer, D.: 1994, 'Epistemological Beliefs in Introductory Physics', Cognition and Instruction 12, 151-183.

Hammer, D.: 1995, 'Epistemological Considerations in Teaching Introductory Physics', Science Education 79, 393-413.

Hawkins, D.: 1990, 'Defining and Bridging the Gap', in Duckworth, E. et al. ed., Science Education: A Minds-On Approach for the Elementary Years, Lawrence Erlbaum Ass., Hillsdale NJ, 1990.

Heering, P.: 2003, 'History - Science - Epistemology: On the use of historical experiments in physics teacher training'. In: McComas, W. F. ed., Proceedings of the 6th International History, Philosophy and Science Teaching Group meeting. (Denver,USA). [File 58 on CD ROM from IHPST.ORG.]

Heering, P.: 2000, 'Getting Shocks: Teaching Secondary School Physics through History', Science and Education 9, 363-373.

Hoddeson, L. H.: 1971, 'Pilot Experience of Teaching a History of Physics Laboratory', American Journal of Physics 39, 924-928.

Holton, G.: 2002. 'The Project Physics Course, Then and Now', Science and Education 12, 779786.

Homberg, W.: 1693, 'Nouveau Phosphore', Memoires de L'Academie Royale des Sciences X, $1730,445-448$.

Hughes-McDonnell, F. J.: 2000, 'Circuits and Pathways of Understanding: "I can’t believe we're actually figuring out some of this stuff", Dissertation, Harvard University, Cambridge MA.

Inhelder, B., Sinclair, H., and Bovet, M.: 1974, Learning and the Development of Cognition, S. Wedgwood, trans., Harvard University Press, Cambridge MA.

Koenig, R.L: 1889, Catalogue des Appareils D'Acoustique, Paris, France. 
Kohl M.: 19--, Physical Apparatus / Vol. II. Apparatus and Supplies for General Use. Introduction to Physics. Mechanics. Wave Theory. Acoustics. Optics. Heat. Meteorology. Cosmology, vol II \& III, Chemnitz, Berlin, Germany.

Kipnis, N.: 1996, 'The 'Historical-Investigative' Approach to Teaching Science', Science and Education 5, 277-292.

Mayer, A. M.: 1878, Sound: ...Experiments...for the use of students, Appleton and Co., NY.

McEwan, N.: 1988, 'Charles Williams, Jr., Boston, Mass.: An early significant telegraph instrument maker, 1850 - 1870s', http://www.telegraph-office.com/pages/Charles_Williams.html

McGinnis, J. R. and Oliver, J. S.: 1998, 'Teaching about Sound: A Select Historical Examination of Research', Science and Education 7, 381-401.

McKinney, A. W: 2004, 'Shaping history: Five students, three artifacts, and the material, social and economic lives of late nineteenth-century butter-makers', Dissertation, Harvard University, Cambridge MA.

Morrison, P.: 1985, 'Knowing Where You Are', in Morrison, P. ed., Nothing is Too Wonderful To Be True, American Institute of Physics Press, Woodbury NY 1995.

Oersted, J. C.: 1820, 'Experiments on the Effect of a Current of Electricity on the Magnetic Needles", Annals of Philosophy, 16, 1820, 273-276.

Pantalony, D.: 2005, 'Rudolph Koenig's Workshop of Sound: Instruments, Theories, and the Debate over Combination Tones', Annals of Science, 62, 57-82.

Pantalony, D.: 2002, 'Rudolph Koenig, Hermann von Helmholtz and the birth of modern acoustics', Dissertation, University of Toronto, Toronto, Ontario.

Piaget, J.: 1926 (1983), The Child's Conception of the World, J. and A. Tomlinson, trans., Rowman \& Allanheld, Totowa NJ.

Piaget, J.: 1936 (1954), The Construction of Reality in the Child, M. Cook, trans, Basic Books, NY.

Pickering, E.C.: 1869, 'On the Experiment of Lissajous', Journal of the Franklin Institute, 87, 55-58.

Pickering, E.C.: 1873, Elements of Physical Manipulation, Houghton, Boston MA.

Prescott, G.B.: 1878, The Speaking Telephone, Talking Phonograph and other Novelties, D Appleton \& Co. NY.

Schneier, L.: 1995, 'Apprehending Poetry: A Case Study of a Group of Six High School Students'. Dissertation, Harvard University, Cambridge MA.

Schweigger, J. S.: 1834, 'On a general Electro-Magnetic and Magneto-Electric Formula', American Journal of Science 356-359.

Steinberg, R.: 2000, 'Computers in teaching science: To simulate or not to simulate', American Journal of Physics, Physics Education Research Supplement, 68, 537-541.

Stevens, K.: 2005, 'Lab Journal' for SP 726.

Teichmann, J.: 1999, 'Studying Galileo at Secondary School: A Reconstruction of His 'Jumping-Hill' Experiment and the Process of Discovery', Science and Education 8, 121136.

Turner, S.: 1996, 'Demonstrating Harmony: Some of the many devices used to produce Lissajous curves before the oscilloscope', Rittenhouse 11, 33-51.

Tweney, R.: 2006, 'Discovering Discovery: How Faraday Found the First Metallic Colloid', Perspectives on Science, 14, in press.

Tyndall, J. 1867 (1889), Sound, Appleton and Co., NY.

Van Heuvelen, A.: 1991, 'Learning to think like a physicist: A review of research-based instructional strategies', American Journal of Physics 59, 891-897.

Venville, G., Wallace, J. et al.: 2002, 'Curriculum Integration: Eroding the High Ground of Science as a School Subject?', Studies in Science Education 37, 43-84. 
Venville, G., Wallace, J. et al.: 2000, 'Bridging the Boundaries of Compartmentalized Knowledge: student learning in an integrated environment', Research in Science and Technological Education 18, 23-35.

Volta, A.: 1800, 'On the Electricity excited by the mere Contact of conducting Substances...', Philosophical Transactions, 289-311.

\section{NOTES}

${ }^{1}$ For full narrations of "Critical Explorations" conducted across many consecutive sessions, see McKinney 2004, Duckworth 2001, Cavicchi 1999, Schneier 1995.

${ }^{2}$ On a previous day, Debbie Douglas and I examined each of the phones described here, and many others. We did not take anything apart. Before the class met, Debbie had never before opened up these phones.

${ }^{3}$ Charles Williams, Jr. was an influential telegraph instrument maker in Boston. His shop at 318 Washington St. from 1850 to 1856, when it relocated to 109 Court Street in Boston. Thomas Watson apprenticed to Charles Williams, and he together with Alexander Graham Bell innovated the early telephone in an attic workshop of Williams shop (McEwan 1988).

${ }^{4}$ The voltaic pile that we observed at the Burndy Library is now in the Historical Scientific Instruments Collection at the Peabody Museum of Natural History, Yale University. Its catalogue number there is YPM 1.446.

${ }^{5}$ The students' finding about the pressed copper-zinc disc was new for me, their teacher. I had previously taken a history of science course in which I had been shown the very same Voltaic pile (see endnote 4) through a glass case. That professor remarked on the superfluity of the pile's bottom disc; being extraneous for the effect, he said it imputed ignorance on the maker's part. With the pile kept behind glass, there was no way to open it up, to learn that all discs were bimetallic and that the disc's fabrication technique, not lack in understanding the chemical couple, guided the maker's construction.

${ }^{6}$ Dick did this many weeks later, by filing the copper bottom and sides of several pennies and stacking them up with moist felt separators. Leaky fluid between the layers diminished the voltage readings that he took.

${ }^{7}$ What Dick constructed was a variant of the Kundt tube, a means of visualizing sound in a tube with instructional precedence. For example, see Tyndall 1867, Pickering 1873, Carman 1955, University of Maryland demonstration by Robert Berg ( http://www.physics.umd.edu/lecdem/services/demos/demosh3/h3-05.htm ) and the San Francisco Exploratorium exhibit (http://www.exploratorium.edu/xref/exhibits/visible_effects_of_the_inv.html ) In these other demonstrations, materials placed inside the tube include Lycopodium powder, cork dust, and water. After class, I tried cork dust and lycopodium powder with our speaker tube, but produced no motions in the dust, which statically adhered to the sides of the tube.

${ }^{8}$ After class, I tried the speaker-tube, keeping the amplitude fixed, and dialing through frequencies. Of the multiple audible resonances, the loudest at $166 \mathrm{~Hz}$, correlated with the fundamental for a closed tube having a nearly $2 \mathrm{~m}$, like ours. Subsequently, I asked Dick why he began using only high frequencies. He recalled that after correcting his calculation, he reasoned that high frequencies would put short waves in the tube. He thought it would be easier to see shorter waves.

${ }^{9}$ The historical tuning forks described here will be relocated to the MIT Museum collection.

${ }^{10}$ The Lissajous figures were first analyzed in 1815 by two American mathematicians, in the context of mechanical motions. In describing the apparent motions of the Earth as they would be viewed in the sky of an observer on the moon, Vermont mathematician James Dean likened the Earth's path to the pattern produced by a double, or Y-suspended, pendulum. Mathematical prodigy Nathanial Bowditch expressed the motions of mutually orthogonal oscillations in drawing constructions and mathematical form (Crowell 1981). French physicist Jules Lissajous produced the figures acoustically in 1857, without knowing of the American precedents in analyzing mechanical motions (Crowell 1981, Turner 1996).

11 David Pantalony and Steve Turner used Koenig tuning forks and laser light sources to demonstrate Lissajous figures at the University of Toronto on October 21, 1999. First tests of MIT's newly re-identified instruments were conducted by Markos Hankin, David Pantalony and me. Hankin wired up a car battery and Carbon Pile Power Resistor and put the forks in parallel. (The resistor consists of approximately 50 $2 " x 2 " x 1 / 8$ " thick graphite tiles, stacked together along their thickness and pressed against one another with a clamping screw. Current flows from one end or the "pile" to the other; the resistance is determined by the 
degree of contact between the faces of the tiles and hence can be adjusted by varying the clamping pressure. This allows for a very wide range of resistance while at the same time tolerating very high currents since the ohmic heating is spread over a large volume of material.) There was suspense in starting a fork for the first time, connecting in the battery, tightening the interrupter screw to just barely touch the fork, and waiting for sound. After nudging and adjusting, the sound came. A laser beam, reflected off the fork's mirror, jiggled where it struck a wall. It took yet more coaxing to add the second, crosswise fork into the circuit, bring out its different tone, and reorient the beam to hit its mirror as well. We spotted the twice-reflected beam where it struck something nearby: a small, revolving figure-eight! Following this test-run, I polished the mirrors and cleaned off oil that darkened the forks and interrupters while Hankin replaced clipleads with more stable wiring. After these improvements, the forks rang beautifully.

${ }^{12}$ The two octave forks were Ut2 $256(128 \mathrm{~Hz})$, and Ut3 $512(256 \mathrm{~Hz})$.

${ }^{13}$ For example, one physics simulation software is made up of 20 Java simulators that students can manipulate to compare physics effects, ED452061, "CPU--Constructing Physics Understanding[TM]", (New York; 2000). See Steinberg 2000 for contrasting and productive uses of simulations in physics instruction.

${ }^{14}$ The Joseph Henry 1830s electromagnet that we observed at the Burndy Library is now in the Historical Scientific Instruments Collection at the Peabody Museum of Natural History, Yale University. Its catalogue number there is YPM 1.445.

${ }^{15}$ The historical coil was likely made by Boston instrument-maker Daniel Davis Jr., and appears as Figure 107, p. 165 in his Manual (1842).

${ }^{16}$ Johann Schweigger (1779-1857) was professor of chemistry at the University of Halle and editor of a leading chemical journal. See Cavicchi 2003.

${ }_{17}^{17}$ A reversing switch connected the conductor to a car battery and carbon pile resistor.

${ }^{18}$ I thank Larry Principe for suggesting Homberg's experiment for my class, advising me about ways it might be performed and needed apparatus, and answering many other questions. Krystyn Van Vliet accommodated our experiment in her lab and gave us access to a propane torch, hood, and balance. Jim Bales advised me about setting up the darkroom part of the experiment. Eileen Huang, Laura Trudel, and Janet Schrenk provided other support. The students worked from my translation of Homberg's text.

${ }^{19}$ Wilhelm Homberg (1652-1715) worked at the Paris Academy of Sciences where he researched acids, alkalis, and light-sensitive materials.

${ }^{20}$ Wintergreen lifesavers exhibit an enhanced example of triboluminescence, the phenomenon Homberg was exploring. We crushed the materials on black and white ASA1600 film and developed the film immediately in the dark. 